\title{
Adaptive Distributed Inter Frame Space for IEEE 802.11 MAC Protocol
}

\author{
Ja'afer AL-Saraireh', Saleh Saraireh"2, Mohammad Saraireh ${ }^{3}$, Mohammed Bani Younis ${ }^{2}$ \\ ${ }^{1}$ Princess Sumaya University for Technology, Amman, Jordan \\ ${ }^{2}$ Philadelphi University, Amman, Jordan \\ ${ }^{3}$ Mutah University, Karak, Jordan \\ Email: sarjaafer@yahoo.com, saleh 53@yahoo.com, m sarayreh@mutah.edu.jo, \\ myunis@philadelphia.edu.jo
}

Received 5 May 2014; revised 5 June 2014; accepted 23 June 2014

Copyright (C) 2014 by authors and Scientific Research Publishing Inc.

This work is licensed under the Creative Commons Attribution International License (CC BY).

http://creativecommons.org/licenses/by/4.0/

c) (i) Open Access

\begin{abstract}
In this research, an Adaptive Distributed Inter Frame Space (ADIFS) has been proposed for IEEE 802.11 Medium Access Control (MAC) protocol. The aim of this approach is to improve Quality of Services (QoS) for IEEE 802.11 MAC protocol in single-hop wireless network. The proposed approach is based on traffic type, Collision Rate (CR), Collision Rate Variation (CRV) and Packet Loss Rate. These parameters are used to adjust the DIFS at runtime. The adjusted DIFS is employed to enhance service differentiation at the MAC layer in single-hop wireless networks. The proposed approach contributes to the enhancement of the average QoS for high priority traffic by $32.9 \%$ and $33.4 \%$ for the 5 and 10 connections, respectively. While the average QoS for the low priority traffic is improved by $14.3 \%$ and $18.2 \%$ for the 5 and 10 connections, respectively. The results indicate that, the proposed approach contributes in the enhancement of the QoS in wireless network.
\end{abstract}

\section{Keywords}

DCF, Collision Rate, Packet Loss, Average Delay, ADIFS

\section{Introduction}

The random transmission of applications over the wireless medium may lead to incomprehensible or unpredictable results [1]. Therefore, a controller, which manages access to the medium of the shared resources is an essential tool for achieving a successful transmission process between the communicating parties, and ensuring access is fair and suitable [2].

The MAC protocol in wireless networks is a protocol that controls access to the shared medium, by applying 
rules and procedures that permit the communication pairs to communicate with each other in an efficient and fair manner [3] [4].

The IEEE 802.11 MAC Distributed Coordination Function (DCF) has two access techniques [5]. The first has two-way handshake known as basic access technique, while the other one has four-way handshake procedures [6].

The basic access method based on the status of channel, so first of all it examines the channel status. If the channel is busy, the node is waiting and monitoring the channel status until it is idle for a period of time called the DIFS. Then the node generates a random back-off interval before transmitting to minimize the probability of multiple nodes concurrently transmission [7]-[9].

The minimum DIFS value is $20 \mu \mathrm{s}$ and the maximum DIFS is $140 \mu \mathrm{s}$ [5]. The minimum value is selected to be longer than the Short Inter Frame Space (SIFS) that is identified for control frames, such as an acknowledgement (ACK) frame, while the maximum value is chosen in order to minimize the wasted time slots by avoiding an excessively long defer of data packets.

This paper is organized as follows: The previous studies for providing service differentiation are presented in the following section. A description of the proposed approach is presented in Section 3. In Section 4, the simulation model is introduced. The results and discussions are presented in Section 5. In Section 6, the paper is concluded.

\section{Related Works}

Most of the proposed priority-based approaches were aimed to support service differentiation by providing different MAC parameter values. The previous works enabled higher priority classes to access the medium faster than low priority classes. For instance, faster access could be provided by assigning a smaller Contention Window (CW) causes a smaller Back-off Interval (BI) as reported in [2] [3] [6] [10]-[15] or by assigning smaller Inter Frame Space (IFS) as reported in (Deng and Chang, 1999), and (Ksentini et al., 2004).

DIFS parameter has been studied for providing service differentiation among different traffic priorities [16]. The value of DIFS in these studies was statically assigned for each class. However, less effort has been made for tuning the DIFS for various traffic types.

In Zhang and Ye (2004), the length of DIFS was computed based on the ratio between the value of estimated transmission rate and total transmission rate [17]. This technique required a significant modification to the IEEE 802.11 DCF scheme.

Sung and Yun (2006) proposed a technique which is called Enhanced Distributed Coordination Function (EDCF) protocol [18]. This technique used Pareto database to store network configuration. For each new configuration the proposed scheme required comparing the current configuration with the already stored in the Pareto curve.

Using IFS is another approach to enhance service differentiation in the IEEE 802.11 MAC protocol. It is based on: 1) using the existing IFS values defined by the standard such as SIFS, Point Inter Frame Space (PIFS), and DIFS and 2) using new IFS values. Different schemes were proposed based on the already available IFS values. For example, the proposed approaches in [14] [19] [20] used PIFS and DIFS values to differentiate between time-sensitive and time-insensitive applications. Some other approaches used new IFS values to differentiate between high and low priority traffic. These new IFS values were based on allocating the low priority traffic longer IFS value than the IFS value of high priority traffic.

Other studies such as [4] [7] [8] [12] [21] were proposed to provide service differentiation based on the distributed function of the standard. These schemes were based on modifying the back-off time of the IEEE 802.11 MAC protocol. Although significant research efforts have been carried out on supporting service differentiation in IEEE 802.11 DCF by adopting the priority-based scheme, several issues have still not been considered.

In this paper, the following points are considered for providing service differentiation in the basic IEEE 802.11 DCF scheme: 1) MAC protocol parameters such as DIFS is dynamically adjusted, 2) different QoS metrics such as throughput, collision rate, packet loss, delay and jitter.

\section{Proposed Approach Description}

An ADIFS composes of four main parts as shown in Figure 1. The first part is traffic classification, which classifies the traffic into high and low priorities. The second is the recording part. Each node recorded the number of 


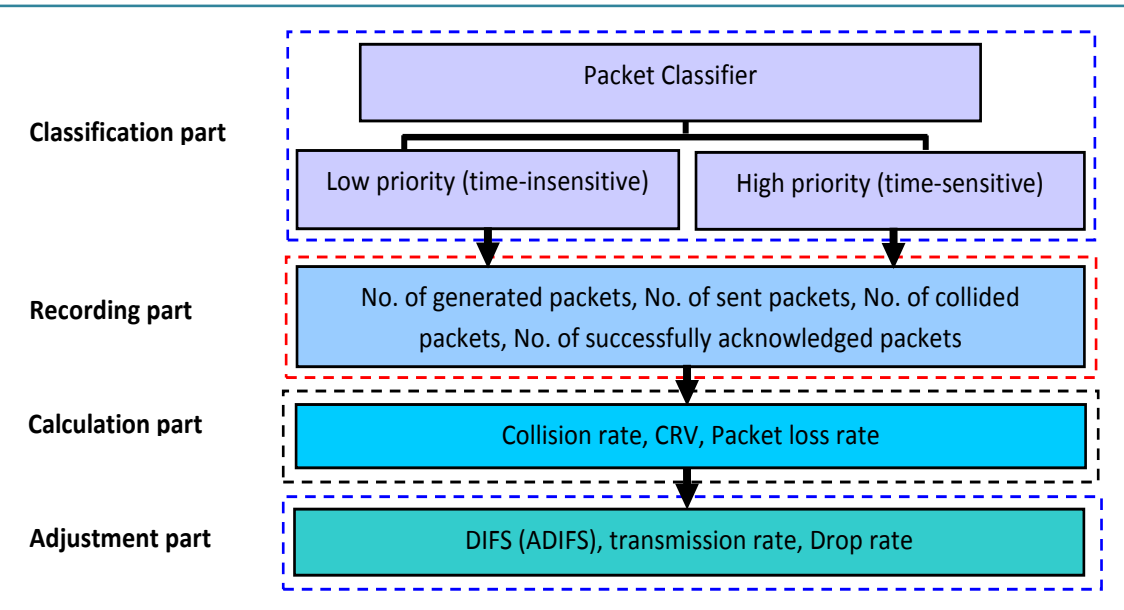

Figure 1. Adaptive distributed inter frame space.

generating packets, sent packets, successfully acknowledged packets, and collided packets. The third is calculation part, where $C R, C R V$, and $l[N]$ values are computed and fed to the final part, the decision on choosing an appropriate parameter values.

The following equation is used to compute $C R$

$$
C R_{\text {current }}[N]=\frac{\operatorname{Num}(\text { collisions }[N])}{\operatorname{Num}(\text { collisions }[N])+N u m(\text { successful }[N])}
$$

where $\operatorname{Num}($ collisions $[N])$ is the number of collisions for node $N$; Num(successful $[N]$ ) represents the number of packets that have been successfully acknowledged for node $N ; C R_{\text {current }}[N]$ is the current collision ratio of node $N$. The $C R V$ value of each node is calculated based on Equation (2).

$$
C R V[N]=C R_{\text {current-average }}[N]-C R_{\text {previous-average }}[N]
$$

where $C R V[N]$ is the collision ratio variation innode $N ; C R_{\text {current-average }}[N]$ and $C R_{\text {previous-average }}[N]$ are the current and the previous average collision ratio, respectively. The $C R V$ provides values within [ -1 to 1$]$. The packet loss rate for node $N_{i},\left(l\left[N_{i}\right]\right)$ is calculated using Equation (3).

$$
l\left[N_{i}\right]=1-\frac{N u m\left(\text { sucess_Ack }\left[N_{i}\right]\right)}{\text { Num }\left(\text { gen } \_ \text {packets }\left[N_{i}\right]\right)}
$$

where Num(sucess_Ack $\left[N_{i}\right]$ ) is the number of successfully received acknowledgements for a node $N$; $i$ stands for high priority class, and Num (gen _ packets $\left[N_{i}\right]$ ) is the number of generating packets at the sender.

For high priority traffic, when the $C R V$ value of a high priority node $\left(C R V\left[N_{i}\right]\right)$ is greater than zero, the proposed scheme examines the packet loss rate $\left(l\left[N_{i}\right]\right)$, if the packet loss rate is below the threshold (i.e. $l\left[N_{i}\right]<l_{-}$ths $\left.\left[N_{i}\right]\right)$, then DIFS length of high priority $\left(\operatorname{ADIFS}_{\text {new }}=\left[N_{i}\right]\right)$ is set equal to DIFS init $_{\text {(i.e. }}$ $A D I F S_{\text {init }}=50 \mu \mathrm{s}$ as defined in (IEEE, 1999)), in order to give low priority traffic a greater chance to access the channel. The minimum length of $\left(\right.$ ADIFS $\left._{\text {new }}=\left[N_{i}\right]\right)$ is limited to one slot time (one slot time equal to 20 $\mu$ sas defined in [5]). If the packet loss rate exceeds the packet loss rate threshold (i.e. $l\left[N_{i}\right]<l_{-}$ths $\left[N_{i}\right]$ ), the DIFS of high priority traffic $\left(A D I F S_{\text {new }}=\left[N_{i}\right]\right)$ is reduced by one slot time, to reduce the delay and to prevent an excessive packet loss for high priority packets. When the $C R V\left[N_{i}\right]$ of high priority traffic is less than zero, the adaptive approach examines the packet loss rate $l\left[N_{i}\right]$ value, if this value is below the packet loss rate threshold $\left(l_{-}\right.$ths $\left.\left[N_{i}\right]\right)$, the DIFS of high priority $\left(A D I F S_{\text {new }}=\left[N_{i}\right]\right)$ is set equal to DIFS init, while if the packet loss rate value $l\left[N_{i}\right]$ is above the packet loss rate threshold $\left(l_{-}\right.$ths $\left.\left[N_{i}\right]\right)$, the DIFS value of high priority packets $\left(\right.$ ADIFS $\left._{\text {new }}=\left[N_{i}\right]\right)$ is updated as given in Equation (4).

$$
\operatorname{ADIFS}_{\text {new }}\left[N_{i}\right]=\operatorname{DIFS}_{\text {init }}\left(1+C R V\left[N_{i}\right]\right)
$$

For low priority traffic, when the $C R V\left[N_{i}\right]$ value is larger than zero, this implies that the number of con- 
tending nodes is increased; and the probability of collisions is increased, since the current collision ratio is larger than the previous one. Therefore the $\left(\right.$ ADIFS $\left._{\text {new }}=\left[N_{i}\right]\right)$ length is increased and is updated using Equation (5).

$$
A D I F S_{\text {new }}\left[N_{i}\right]=\operatorname{DIFS}_{\text {init }}+\left(f * C R V\left[N_{j}\right] * A D I F S_{\text {new }-1}\left[N_{j}\right]\right)
$$

where $f$ is a scaling factor, with value of $f=3$ as considered in the simulations (Saraireh et al., 2014). If the $C R V\left[N_{i}\right]$ value is less than zero, this means that, the current probability of collisions is smaller than the previous one, and as a result, the proposed approach decreases the $\operatorname{ADIFS}_{\text {new }}\left[N_{i}\right]$ by one slot time as represented in Equation (6).

$$
A D I F S_{\text {new }}\left[N_{j}\right]=A D I F S_{\text {new }-1}\left[N_{j}\right]-(\text { one_slot_time })
$$

To ensure that the lengths of $A D I F S_{\text {new }}\left[N_{i}\right]$ and $\operatorname{ADIFS}_{\text {new }}\left[N_{j}\right]$ are within the specified ranges the following conditions are applied:

In Equation (4), if $A D I F S_{\text {new }}\left[N_{i}\right]<$ one time-slot, then $\operatorname{ADIFS}_{\text {new }}\left[N_{i}\right]=$ one slot.

In Equation (5), if $A D I F S_{\text {new }}\left[N_{j}\right]>$ seven slots then $A D I F S_{\text {new }}\left[N_{j}\right]=$ seven slots.

In Equation (6), if $A D I F S_{\text {new }}\left[N_{j}\right]<D I F S_{\text {init }}$ then $A D I F S_{\text {new }}\left[N_{j}\right]=D I F S_{\text {init }}$.

To avoid starvation for low priority traffic, after each update of the DIFS, the adaptive approach examines the value of this parameter. If DIFS has high values. The proposed scheme sets these parameters as shown in Equation (7).

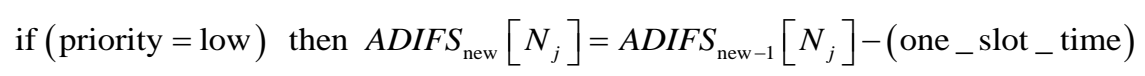

An overview of the adaptive differentiation operation is provided in Figure 2. It is assumed that there are two nodes, one is a high priority and the other is a low priority node. The high priority node is competing with smaller DIFS, while the lower priority node is competing with larger DIFS. Therefore, the high priority node accesses the medium first. A full description of the proposed algorithm is presented in Figure 3.

\section{Simulation Model}

To analyze the proposed ADIFS approach, and compare their functionalities with the standard IEEE 802.11 DCF scheme, network models with different scenarios have been proposed for the simulations by using NS-2.

In this approach, 40 fixed nodes are used, and they are randomly distributed in an area of $100 \mathrm{~m} \times 100 \mathrm{~m}$, and the transmission type is CBR traffic. The nodes are located in the same Independent Basic Service Set to represent a wireless ad-hoc network, as shown in Figure 4. The parameters of simulation are presented in Table 1.

The total offered load in each scenario is more than $110 \%$ of the effective channel capacity (i.e. it is considered 1.6 Mbps without considering the protocol overhead) and more than $90 \%$ of the total channel capacity (i.e. 2 Mbps, with considering the impact of protocol overhead).

\section{Results and Discussion}

In the ADIFS scheme, the CW size is updated according to the Binary Exponential Backoff (BEB) procedure as defined by IEEE 802.11 DCF. In IEEE 802.11 DCF, the ACK frame is assigned as a higher priority over data packets by having a shorter IFS known as SIFS, while data packets have a longer IFS known as DIFS (i.e. SIFS $<D I F S$ ). The same concept is applied for the ADIFS scheme, where the DIFS length is dynamically adjusted for each priority based on the packet loss rate and $C R V$ values.

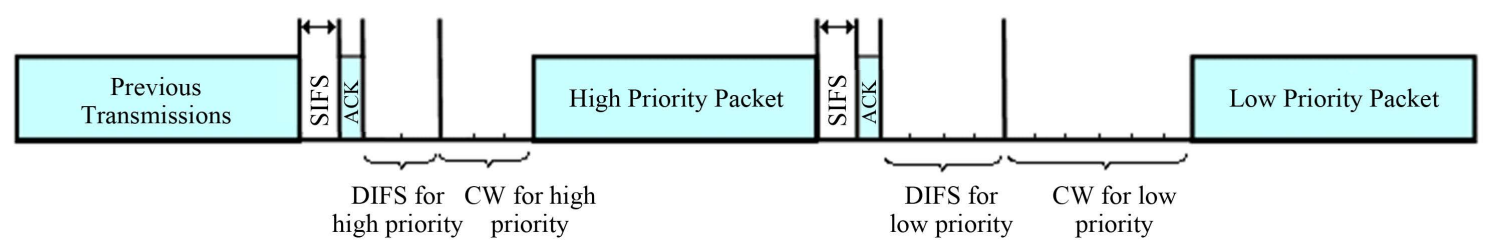

Figure 2. Adaptive differentiation scheme operation. 


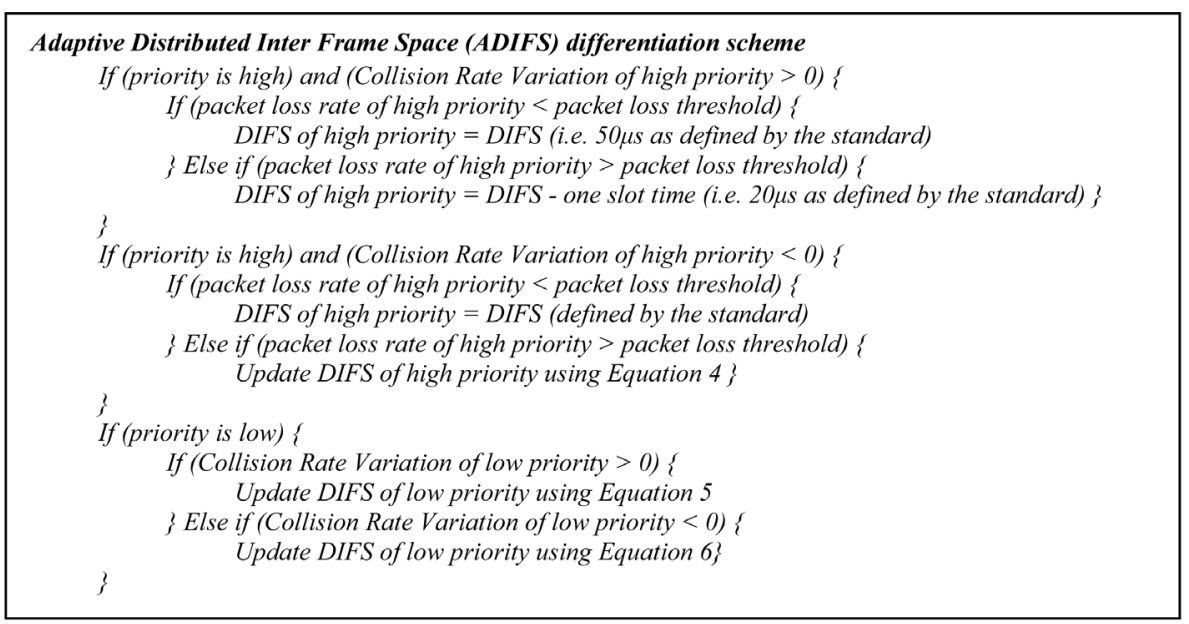

Figure 3. Adaptive differentiation algorithm.

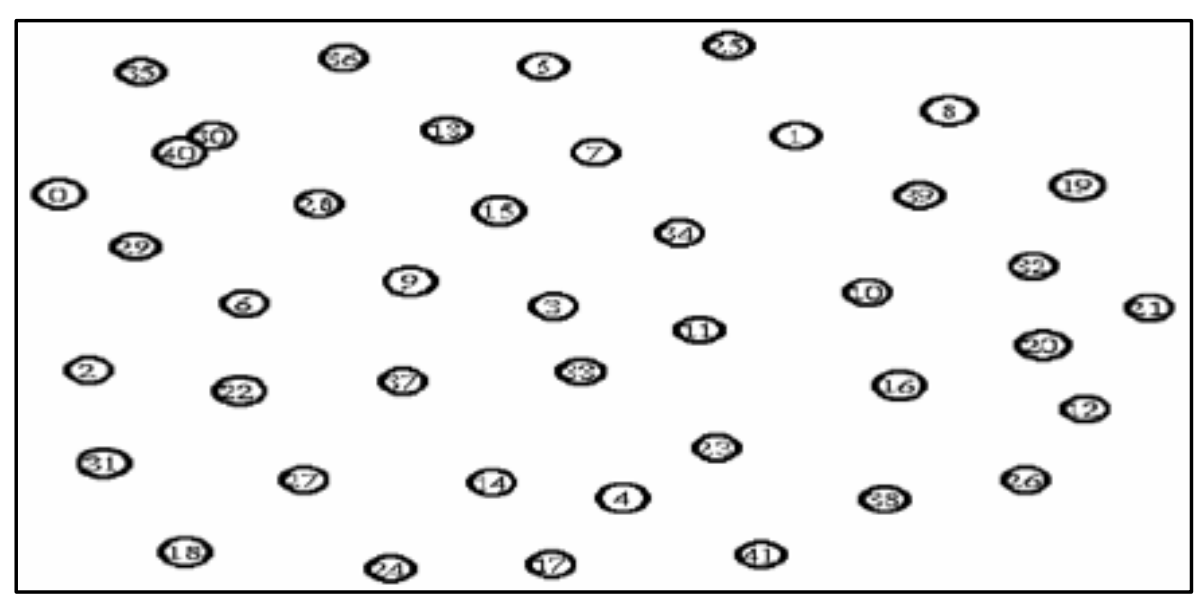

Figure 4. Random independent basic service set single-hop topology.

\begin{tabular}{|c|c|c|c|c|c|c|}
\hline Traffic Type & Packet Size & Scenario & Connection/Priority & Bit Rate & Simulation Time & Run's Number \\
\hline \multirow{3}{*}{ Low Priority } & \multirow{3}{*}{800 Bytes } & \multirow{3}{*}{ Scenario 1} & 3 Low & $480 \mathrm{Kbps}$ & \multirow{5}{*}{$\begin{array}{c}300 \\
\text { Seconds }\end{array}$} & \multirow{5}{*}{10} \\
\hline & & & & & & \\
\hline & & & 2 High & 192 Kbps & & \\
\hline \multirow{2}{*}{ High Priority } & \multirow{2}{*}{512 Bytes } & \multirow{2}{*}{ Scenario 2} & 5 Low & $160 \mathrm{Kbps}$ & & \\
\hline & & & 5 High & 192 Kbps & & \\
\hline
\end{tabular}

As indicated in Table 2, the average delay for the high priority connections is less than $13 \mu$ s. The results indicate that high priority connections have better QoS, with a mean value equal to 86.9\%. This significant improvement in the QoS of high priority traffic is at the cost of low priority traffic. For instance, the first low priority connection has a poor QoS with an average of 45.3\%. This is due to the long waiting time prior to the transmission which lead to high packet drops at the buffer.

The ADIFS approach is also evaluated when the number of nodes for high and low priority is increased. In this scenario, five high priority and five low priority nodes are contended to access the channel. The ADIFS scheme performs well when the number of contending nodes is increased. For instance, in this scenario, the average delay of high priority nodes is less than $28 \mu \mathrm{s}$ in which QoS requirements in terms of delay for the timesensitive applications could be met. When the ADIFS scheme is applied, a high priority node is required to wait 
for a shorter period, so it could get access to the channel earlier than a low priority node. At the time, when a low priority node tries to access the medium, it finds the channel busy and has to wait until the transmission of higher priority packet is complete. Once the channel becomes idle, all nodes commence their back-off duration. Due to shorter lengths of DIFS for high priority nodes, they wait for shorter time periods and start to decrease their back-off time earlier than low priority nodes. This behaviour leads to better performance for the QoS parameters and the average QoS of all connections as depicted in Figures 5(a)-(c) and shown in Table 3. The average QoS for higher priority traffic is $83.5 \%$ with fewer fluctuations and the average QoS for the low priority traffic is $37.1 \%$.

Table 4 summarizes the QoS results for the proposed approach as compared with others for 5 connections.

Table 2. QoS parameters values obtained using the adaptive ADIFS differentiation scheme.

\begin{tabular}{rlccccc}
\hline \multirow{2}{*}{ Bit Rate } & Connection/Priority & $\begin{array}{c}\text { Average delay } \\
(\mu \mathrm{s})\end{array}$ & $\begin{array}{c}\text { Average jitter } \\
(\mu \mathrm{s})\end{array}$ & $\begin{array}{c}\text { Average throughput } \\
(\text { Kbps })\end{array}$ & $\begin{array}{c}\text { Average MAC efficiency } \\
(\%)\end{array}$ & $\begin{array}{c}\text { Average QoS } \\
(\%)\end{array}$ \\
\hline \multirow{2}{*}{$192 \mathrm{Kbps}$} & Connection 1/high & 12.7 & 6.1 & 189.3 & 99.9 & 86.8 \\
& Connection 2/high & 10.0 & 6.0 & 188.5 & 99.9 & 87.0 \\
& Connection 3/low & 1471.5 & 22.3 & 281.7 & 99.9 & 45.3 \\
\multirow{3}{*}{$480 \mathrm{Kbps}$} & Connection 4/low & 709.6 & 9.9 & 304.9 & 99.9 & 54.4 \\
& Connection 5/low & 955.4 & 11.4 & 284.8 & 99.8 & 50.1 \\
\hline
\end{tabular}

Table 3. QoS parameters values obtained using the adaptive ADIFS differentiation scheme for 10 connections.

\begin{tabular}{|c|c|c|c|c|c|c|}
\hline Bit Rate & Connection/Priority & $\begin{array}{l}\text { Average delay } \\
(\mu \mathrm{s})\end{array}$ & $\begin{array}{l}\text { Average jitter } \\
(\mu \mathrm{s})\end{array}$ & $\begin{array}{l}\text { Average throughput } \\
\text { (Kbps) }\end{array}$ & $\begin{array}{c}\text { Average MAC efficiency } \\
(\%)\end{array}$ & $\begin{array}{c}\text { Average QoS } \\
(\%)\end{array}$ \\
\hline \multirow{5}{*}{$192 \mathrm{Kbps}$} & Connection 1/high & 24.3 & 7.03 & 193.8 & 99.7 & 83.9 \\
\hline & Connection 2/high & 26.7 & 6.5 & 188.7 & 99.8 & 82.9 \\
\hline & Connection 3/high & 25.4 & 8.2 & 174.0 & 99.9 & 83.6 \\
\hline & Connection 4/high & 18.3 & 7.2 & 181.6 & 99.8 & 83.6 \\
\hline & Connection 5/high & 27.8 & 7.3 & 178.5 & 99.7 & 83.3 \\
\hline \multirow{5}{*}{$160 \mathrm{Kbps}$} & Connection 6/low & 3859.4 & 61.4 & 86.9 & 99.6 & 39.5 \\
\hline & Connection 7/low & 5009.8 & 60.1 & 71.4 & 99.9 & 29.1 \\
\hline & Connection 8/low & 3263.9 & 46.5 & 80.4 & 99.7 & 33.4 \\
\hline & Connection 9/low & 860.0 & 25.2 & 123.0 & 99.5 & 43.3 \\
\hline & Connection 10/low & 4145.4 & 60.1 & 97.0 & 99.5 & 40.0 \\
\hline
\end{tabular}

Table 4. Comparison of IEEE 802.11 DCF QoS, Saraireh et al., 2014 with proposed schem for 5 connections.

\begin{tabular}{cccccc}
\hline Bit Rate & Connection/Priority & $\begin{array}{c}\text { Average QoS } \\
\text { (\%) Proposed }\end{array}$ & $\begin{array}{c}\text { Average Qos (\%) } \\
\text { (Saraireh et al., 2014) }\end{array}$ & $\begin{array}{c}\text { Average QoS } \\
\text { (\%) Standard }\end{array}$ & $\begin{array}{c}\text { Average QoS (\%) Improvement } \\
\text { (Saraireh } \text { et al., 2014) }\end{array}$ \\
\hline & Connection 1/high & 86.8 & 73.0 & 56.4 & 16.6 \\
(\%) Improvement
\end{tabular}




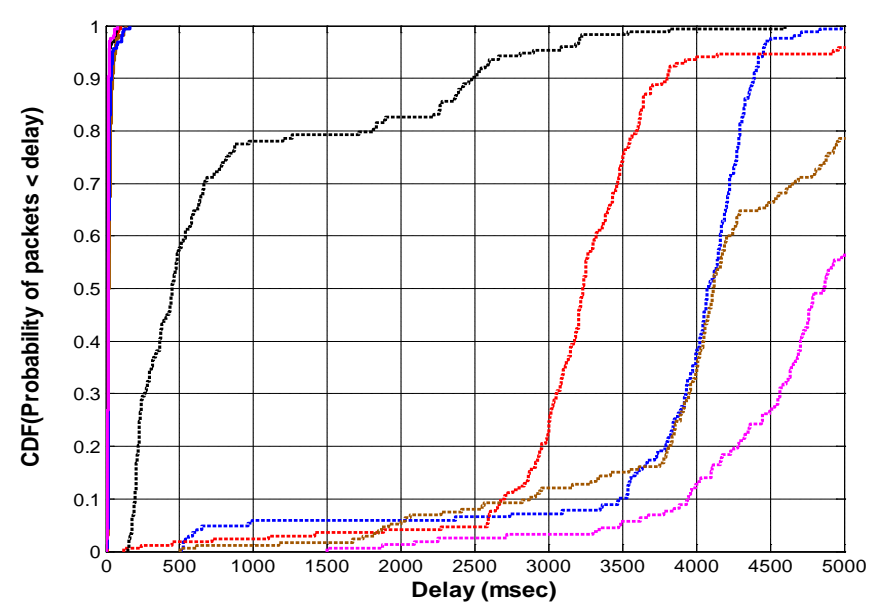

(a)

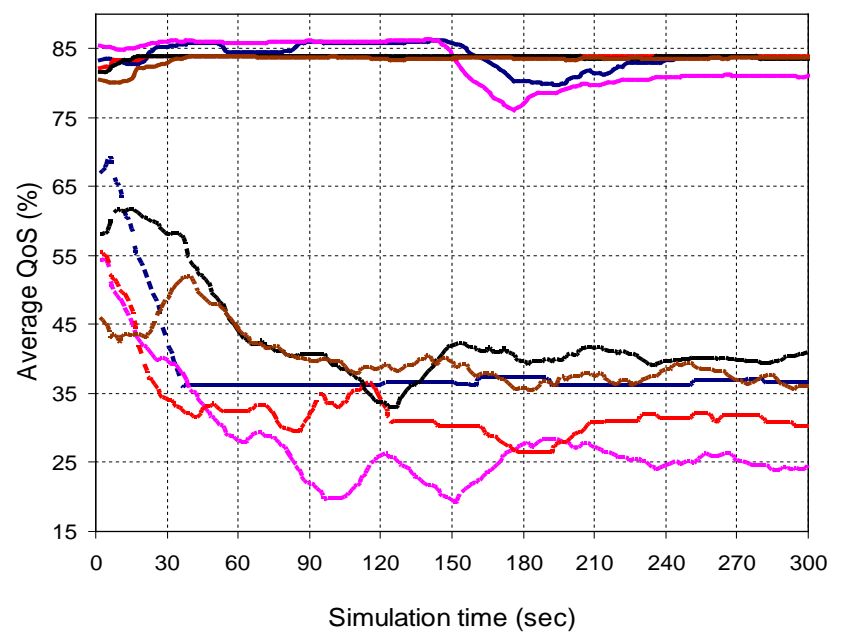

(b)

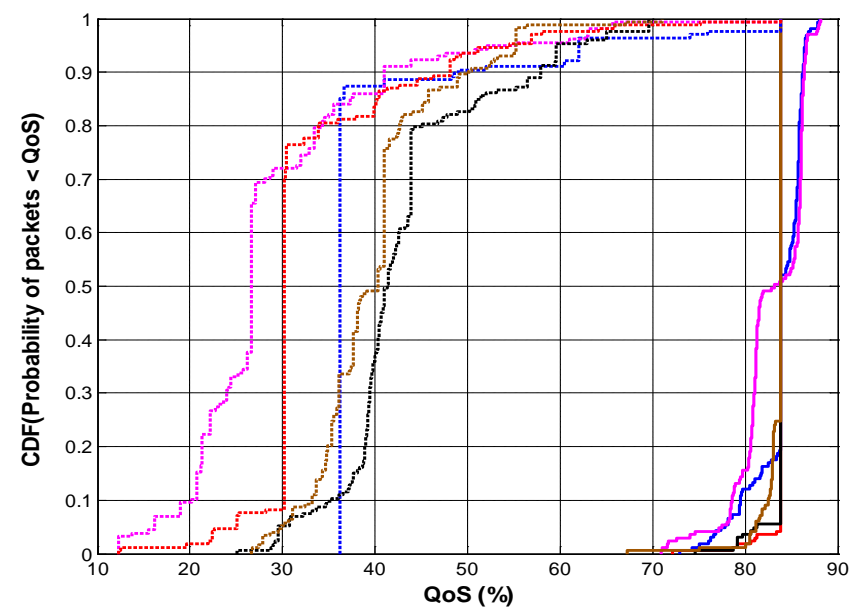

(c)

- Connection 1 (high priority); - Connection 2 (high priority); - Connection 3 (high priority); - Connection 4 (high priority); - Connection 5 (high priority); .... Connection 6 (low priority); .... Connection 7 (low priority); .... Connection 8 (low priority); .... Connection 9 (low priority); .... Connection 10 (low priority).

Figure 5. ADIFS-based differentiation for 10 connections (5 high and 5 low priority nodes). (a) cumulative distribution of delay; (b) average QoS; and (c) cumulative distribution of QoS. 
These results are also shown in Figure 6. The average of QoS of proposed scheme increases from $54 \%$ to 86.9\% for the high priority connections as compared with the standard, while it increases from $72.3 \%$ to $86.9 \%$ as compared with (Saraireh et al., 2014). On the other hand, for low priority connections the average of QoS is improved by $14.3 \%$ and $2.7 \%$ as compared with the standard and (Saraireh et al., 2014), respectively. These results indicate that the use of the proposed approach improves QoS in wireless networks.

Table 5 summarizes the QoS results by using the proposed approach as compared with others for 10 connections. These results are also shown Figure 7. The average of QoS of proposed scheme increases from 50.1\% to 83.5\% for the high priority connections as compared with the standard, while it increases from $72.7 \%$ to $83.5 \%$ as compared with (Saraireh et al., 2014) for the high priority connections. For low priority, the average QoS is enhanced by $18.2 \%$ and $0.4 \%$ as compared with the standard and (Saraireh et al., 2014), respectively.

Table 5. Comparison of IEEE 802.11 DCF QoS, Saraireh et al., 2014 with proposed schem for 10 connections.

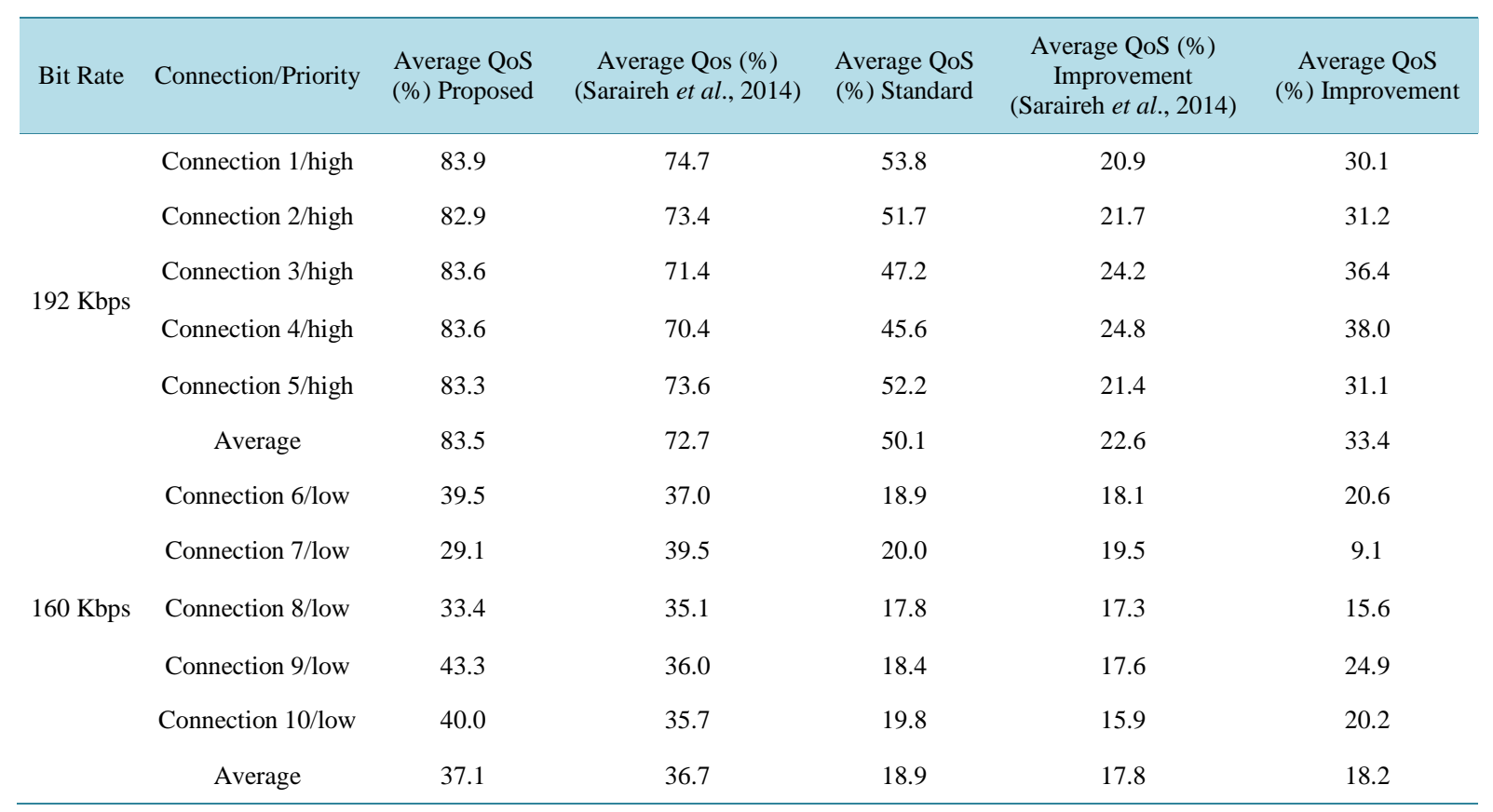

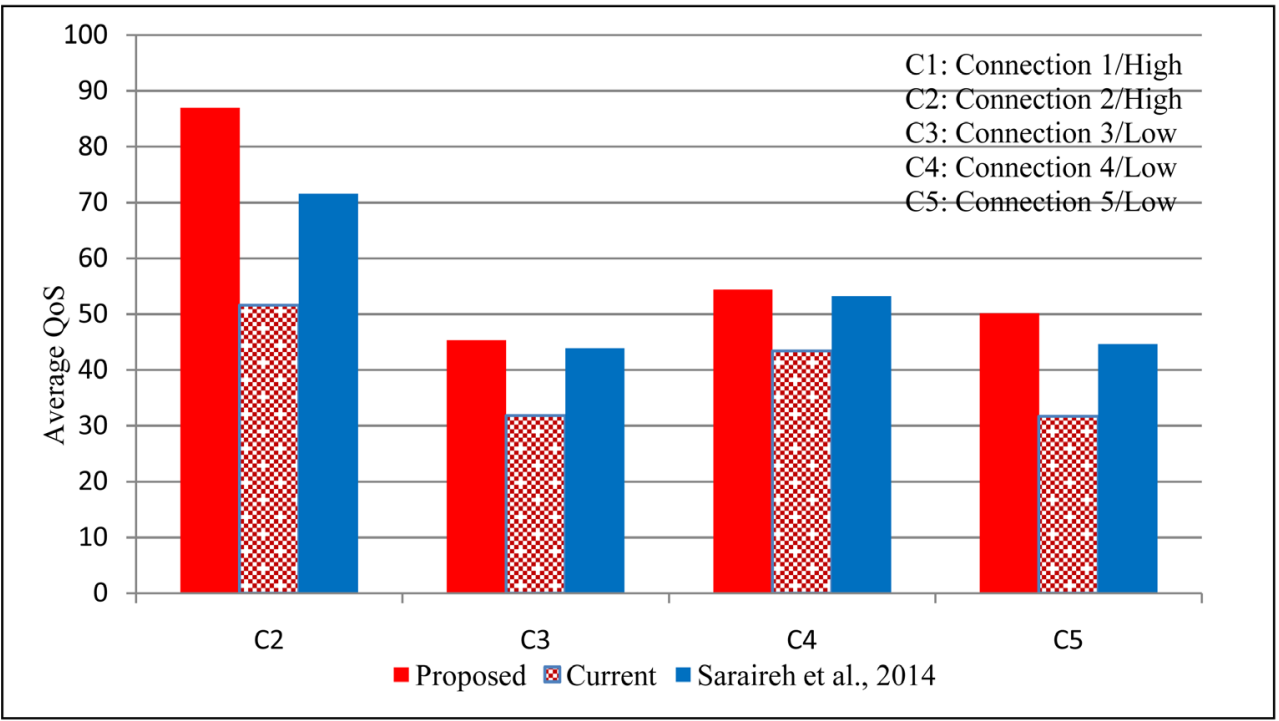

Figure 6. Comparison of IEEE 802.11 DCF QoS, Saraireh et al., 2014 with a proposed scheme for 5 connections. 


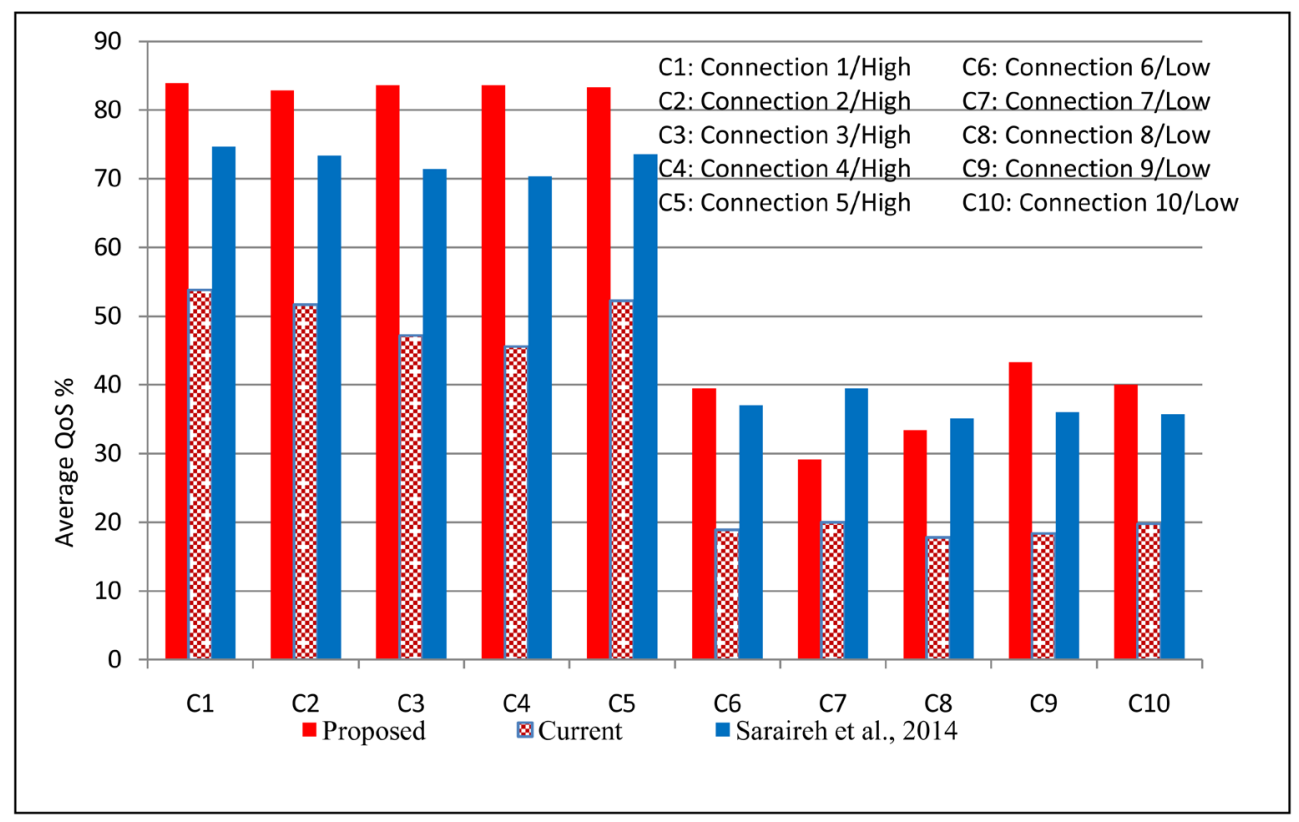

Figure 7. Comparison of IEEE 802.11 DCF QoS, Saraireh et al., 2014 with a proposed scheme for 10 connections.

\section{Conclusions}

In this research, an enhancement to IEEE 802.11 DCF scheme to provide QoS has been developed. The proposed approach based on dynamically adjustment of DIFS at run time depend on traffic types at MAC layer in the single hop network.

The simulation results indicate that, the adaptive approach improves the performance for high and low priority traffics. The results reveal that the adaptive scheme is capable of providing service differentiation and improving the network performance. The results indicate that, the QoS for priority traffics in terms of delay, jitter and throughput are improved for high and low priority traffics using different number of connections.

\section{References}

[1] Saraireh, M., Saraireh, J. and Saraireh, S. (2014) A Novel Adaptive Contention Window Scheme for IEEE 802.11 MAC Protocol. Journal of Trends in Applied Sciences Research, 9, 275-289. http://dx.doi.org/10.3923/tasr.2014.275.289

[2] Balador, A., Movaghar, A., Jabbehdari, S. and Kanellopoulos, D. (2012) A Novel Contention Window Control Scheme for IEEE 802.11 WLANs. IETE Technical Review, 29, 202-212. http://dx.doi.org/10.4103/0256-4602.98862

[3] Raksha, U., Prakash, D. and Sanjiv, T. (2013) Collision Resolution Schemes with Nonoverlapped Contention Slots for Heterogeneous and Homogeneous WLANs. Journal of Engineering, 2013, 1-9. http://dx.doi.org/10.1155/2013/852959

[4] Li, B., Battiti, R. and Yong, F. (2007) Achieving Optimal Performance by Using IEEE 802.11 MAC Protocol with Service Differentiation Enhancements. IEEE Transactions on Vehicular Technology, 56, 1374-1387. http://dx.doi.org/10.1109/TVT.2007.895565

[5] IEEE (1999) IEEE Standard for Wireless LAN Medium Access Control (MAC) and Physical Layer (PHY) Specifications, ISO/IEC 8802-11:1999E.

[6] Deng, D.J., Ke, C.H., Chen, H.H. and Huang, Y.M. (2008) Contention Window Optimization for IEEE 802.11 DCF Access Control. IEEE Transactions on Wireless Communications, 7, 29-35. http://dx.doi.org/10.1109/T-WC.2008.071259

[7] Zhang, M., Gong, C. and Lu, Y. (2008) Dynamic Priority Backoff Algorithm for IEEE 802.11 DCF. Proceedings of the International Conference on Computer Science and Software Engineering, Wuhan, 12-14 December 2004, 956-958. http://dx.doi.org/10.1109/CSSE.2008.901

[8] Lin, C.H., Shieh, C.K., Hwang, W.S. and Ke, C.H. (2008) An Exponential Linear Backoff Algorithm for Conten- 
tion-Based Wireless Networks. Proceedings of the International Conference on Mobile Technology, Applications, and Systems (Mobility '08). http://dx.doi.org/10.1145/1506270.1506324

[9] Mahdieh, G., Naser, M. and Kamal, J. (2013) A Game Theory Based Contention Window Adjustment for IEEE 802.11 under Heavy Load. International Journal of Communication Networks and Information Security (IJCNIS), 5, 93-103. http://dx.doi.org/10.3923/tasr.2014.275.289

[10] Veres, A., Campbell, A., Barry, M. and Sun, L. (2006) Supporting Service Differentiation in Wireless Packet Networks Using Distributed Control. IEEE Journal on Selected Areas in Communications (JSAC), 19, 2081-2093. http://dx.doi.org/10.1109/49.957321

[11] Kim, K., Shin, S. and Kim, K. (2001) A Novel MAC Scheme for Prioritized Services in IEEE 802.11 DCF 802.11a Wireless LAN. Proceeding of IEEE International Conference on ATM and High Speed Intelligent Internet (ICATM), Seoul, 22-25 April 2001, 196-199. http://dx.doi.org/10.1109/ICATM.2001.932084

[12] Barry, M., Campbell, A. and Veres, A. (2001) Distributed Control Algorithms for Service Differentiation in Wireless Packet Networks. Proceeding of 20th Annual Joint Conference of the IEEE Computer and Communications Societies (INFOCOM), Anchorage, 22-26 April 2001, 582-590. http://dx.doi.org/10.1109/INFCOM.2001.916786

[13] Gannoune, L. (2006) A Comparative Study of Dynamic Adaptation Algorithms for Enhanced Service Differentiation in IEEE 802.11 Wireless Ad Hoc Networks. Proceeding of AICT-ICIW'06, International Conference on Telecommunications and International Conference on Internet, Web Applications and Services, 19-25 February 2006, 31-37. http://dx.doi.org/10.1109/AICT-ICIW.2006.4

[14] Deng, J. and Chang, R. (1999) Priority Scheme for IEEE 802.11 DCF Access Method. IEICE Transactions on Communications, 82, 96-102.

[15] Ksentini, A., Naimi, M., Nafaa, A. and Gueroui, M. (2004) Adaptive Service Differentiation for QoS Provisioning in IEEE 802.11 Wireless Ad Hoc Networks. PE-WASUN '04 Proceedings of the 1st ACM International Workshop on Performance Evaluation of Wireless Ad Hoc, Sensor, and Ubiquitous Networks, 39-45.

[16] Aad, I. and Castelluccia, C. (2001) Differentiation Mechanisms for IEEE 802.11. Proceeding Joint Conference of the IEEE Computer and Communications Societies (INFOCOM), Anchorage, 22-26 April 2001, 209-218. http://dx.doi.org/10.1109/INFCOM.2001.916703

[17] Zhang, S. and Ye, C. (2004) On Service Differentiation in Mobile Ad Hoc Networks. Journal of Zhejiang University Science, 5, 1087-1094. http://dx.doi.org/10.1631/jzus.2004.1087

[18] Sung, M. and Yun, N. (2006) A MAC Parameter Optimization Scheme for IEEE 802.11e-Based Multimedia Home Networks. 3rd IEEE, Consumer Communications and Networking Conference, CCNC 2006, 8-10 January 2006, 390394. http://dx.doi.org/10.1109/CCNC.2006.1593053

[19] Shue, S.T. and Shue, T.F. (2001) A Bandwidth Allocation, Sharing and Extension Protocol for Multimedia over IEEE 802.11 DCF 802.11 Ad Hoc Wireless LANs. IEEE Journal on Selected Areas in Communications (JSAC), 19, 20652080.

[20] Banchs, A., Perez, X., Radimirsch, M. and Stuttgen, H. (2001) Service Differentiation Extensions for Elastic and Real-Time Traffic in 802.11 Wireless LAN. Proceeding of IEEE Workshop on High Performance Switching and Routing (HPSR), Dallas, 29-31 May 2001, 245-249. http://dx.doi.org/10.1109/HPSR.2001.923640

[21] Ayyagari, A., Bernet, Y. and Moore, T. (2000) IEEE 802.11 Quality of Service. White Paper, 1-10. https://mentor.ieee.org/802.11/dcn/00/11-00 
Scientific Research Publishing (SCIRP) is one of the largest Open Access journal publishers. It is currently publishing more than 200 open access, online, peer-reviewed journals covering a wide range of academic disciplines. SCIRP serves the worldwide academic communities and contributes to the progress and application of science with its publication.

Other selected journals from SCIRP are listed as below. Submit your manuscript to us via either submit@scirp.org or Online Submission Portal.
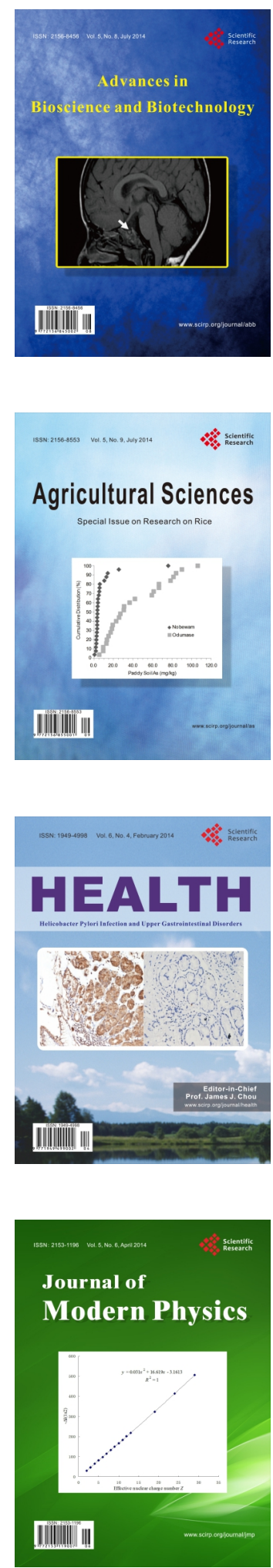
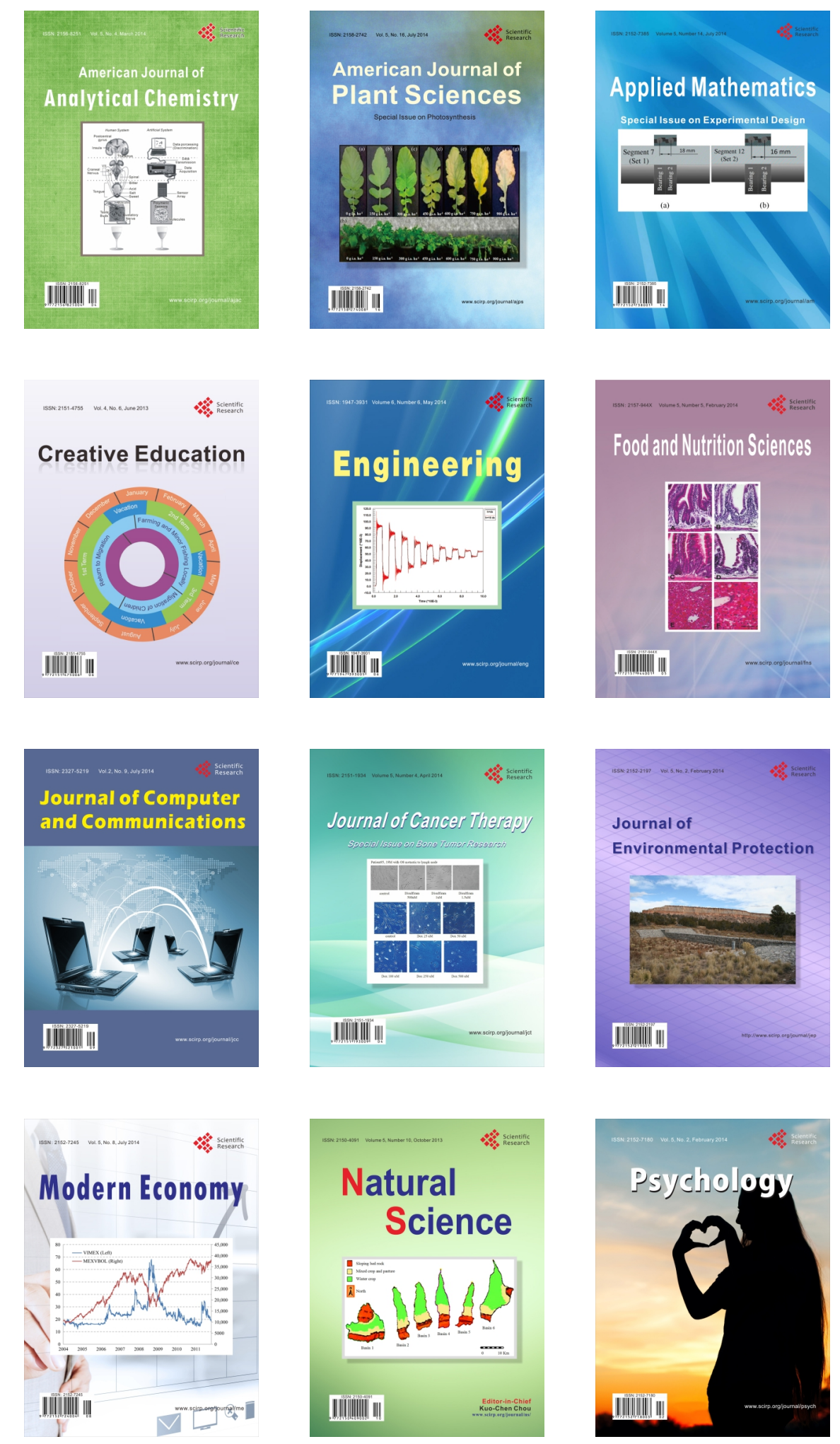